DOI 10.5216/ia.v46ied.especial.70042

\title{
TRAÇOS DA PEDAGOGIA DE PAULO FREIRE NA SALA DE AULA DO ENSINO SUPERIOR: O RIGOR DIALÓGICO NA AÇÃO DIDÁTICA HUMANIZADORA
}

\author{
BRUNA SOLA DA SILVA RAMOS \\ Universidade Federal de São João del-Rei (UFSJ), São João del-Rei, Minas Gerais, Brasil \\ MARGARETE SAMPAIO \\ Universidade Estadual do Ceará (UECE), Fortaleza, Ceará, Brasil \\ ALEXANDRE SAUL \\ Universidade Católica de Santos (UNISANTOS), Santos, São Paulo, Brasil
}

\begin{abstract}
Resumo: No presente artigo, discutimos a ação didática humanizadora no Ensino Superior, buscando traços do rigor dialógico freireano em experiências vivenciadas pelos autores em suas instituições de origem. Percorrendo caminhos da práxis freireana, apresentamos os pressupostos e categorias temáticas que orientam ações de ensino vivenciadas na Graduação e na Pós-Graduação, tomando a matriz crítico-dialógica de Paulo Freire como referencial para o planejamento e o desenvolvimento de disciplinas acadêmicas. No âmbito da sala de aula, apresentamos e discutimos duas propostas de ação didática, uma presencial e outra remota, nas quais buscamos partilhar caminhos possíveis para a construção de relações humanizadoras entre professores(as) e estudantes envolvidos na busca autêntica pelo conhecimento. Na base da proposição deste artigo, anuncia-se a vivência relacional que vem permitindo aos autores participar de uma rede colaborativa e coletiva de construção de conhecimentos que conectam nossas ações e fortalecem nossas lutas no campo da educação libertadora.
\end{abstract}

Palavras-chave: Ensino Superior. Ação Didática. Diálogo. Paulo Freire.

INTRODUÇÃO

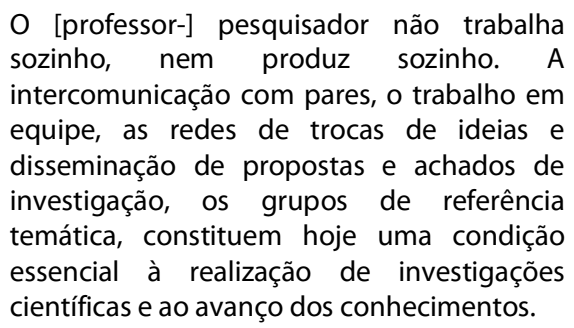

(Gatti, 2005, p. 124)

Na esteira do enunciado de Gatti (2005), compreendemos que a força de nossos estudos, pesquisas e práticas educativas está diretamente relacionada à formação de 
redes de colaboração que promovam trocas de experiências e de aprendizados, e que favoreçam a construção coletiva do conhecimento. O presente artigo é fruto de uma dessas redes colaborativas e nasce do diálogo que as autoras e o autor vêm estabelecendo entre si, especialmente com a Cátedra Paulo Freire da PUC/São Paulo e com a Rede Freireana de Pesquisadores, ambas coordenadas pela Profa. Dra. Ana Maria Saul; e com a Cátedra Paulo Freire da Universidade Federal de Pernambuco, coordenada pela Profa. Dra. Eliete Santiago.

O trabalho desenvolvido em nossas instituições, inseridas em duas regiões do país, o Sudeste e o Nordeste, vem sendo alimentado pelas possibilidades abertas pelo diálogo interinstitucional. As ações colaborativas que temos experimentado vêm gestando reflexões e práticas potentes, especialmente no que tange à (re)criação da síntese cultural, necessária ao alargamento das leituras, dos cenários e dos modos de produção do conhecimento.

Nesse percurso, temos enveredado pelo alargamento do diálogo com a matriz teórico-epistemológica-metodológica do pensamento freireano', na coordenação das Cátedras e Grupos de Pesquisa situados em nossas instituições superiores, no oferecimento de disciplinas de Graduação e de Pós-Graduação; na orientação de Pesquisas de Iniciação Científica e Mestrado e em ações Comunicativo-Extensionistas, que assumem esta matriz por referencial. Em um contexto de opção ética e responsiva, pelas lentes do referencial freireano, tem origem o presente artigo, feito a seis mãos e composto por três diferentes experiências que se entrecruzam em um cenário de estudos e relações colaborativas.

Neste artigo, colocamos em cena a ação didática humanizadora no Ensino Superior e seu rigor dialógico. Viver uma ação didática autenticamente humanizadora requer coerência entre o pensado, o dito e o vivido. Isso está relacionado a uma compreensão de que o(a) professor(a) trabalha com um repertório de saberes que somente o exercício, teoricamente fundamentado da prática, lhe permitirá construir. Cabe-nos questionar: Qual o lugar do diálogo na ação didática humanizadora?

Com esteio na práxis freireana, compreendemos que o diálogo é um princípio formativo e uma necessidade existencial dos seres humanos, impelindo educadores progressistas a assumirem a horizontalidade necessária em processos pedagógicos que colaborem para que os educandos(as) se tornem, cada vez mais, criticamente comunicativos.

PRESSUPOSTOS FREIREANOS NO PLANEJAMENTO E DESENVOLVIMENTO DE DISCIPLINAS VINCULADAS À CÁTEDRA PAULO FREIRE DA UNISANTOS

A Cátedra Paulo Freire da Universidade Católica de Santos (UniSantos) foi instalada em junho de 2005, pelo então diretor do Centro de Ciências da Educação da UniSantos, prof. Me. Dráuzio da Costa Pires de Campos. A partir de 2018, o prof. Dr. Alexandre Saul, do Programa de Pós-Graduação Stricto Sensu em Educação da Católica de Santos, assume a coordenação da Cátedra.

Nesse contexto, para além de um espaço de homenagem, a Cátedra Paulo Freire passa a configurar-se como um contexto dedicado ao desenvolvimento de 
estudos e pesquisas sobre e a partir do pensamento de Paulo Freire, com vistas à análise de repercussões do pensamento freireano na Região Metropolitana da Baixada Santista (RMBS), em uma perspectiva crítica.

$\mathrm{Na}$ Cátedra são desenvolvidas atividades de ensino que se materializam em práticas de estudo e aprofundamento na obra de Freire. A pesquisa que associa à intenção de compreender a reinvenção do legado freireano na atualidade, com a orientação de investigações teórico-práticas em nível de Graduação e Pós-Graduação. $\mathrm{E}$ a extensão, que gera ações de formação de educadores e projetos que articulam o legado freireano às necessidades da comunidade da RMBS; como é o caso do projeto "Remição de pena pela leitura" ${ }^{2}$, em parceria com a Defensoria Pública de Santos, ainda em fase de estruturação.

Dentre as atividades de ensino já realizadas, destaca-se, nesta seção, alguns dos pressupostos do processo de planejamento e desenvolvimento de disciplinas lecionadas na Pós-Graduação Stricto Senso em Educação da UniSantos, que ficam sob a responsabilidade do coordenador da Cátedra Paulo Freire. Nessas disciplinas o pensamento de Paulo Freire articula-se a temas geradores ${ }^{3}$ dos pós-graduandos e campos de pesquisa da área da Educação como objeto de análise, além de ganhar status de referência teórico-metodológica central para o desvelamento da realidade estudada e o desenrolar do ensino-aprendizagem.

Paulo Freire aponta que a prática educativa, independentemente do nível e/ou modalidade de ensino, é intencional, diretiva, ou seja, não existe prática neutra. Ela explicita formas de distribuição de poder e intervenção no espaço público, e está apoiada em princípios e valores que dirigem as opções feitas em relação às metas e objetivos da educação, ao recorte do conhecimento selecionado para o trabalho pedagógico e ao próprio processo de sua seleção. Trata-se, portanto, de um quefazer ${ }^{4}$ sistemático, o que quer dizer que a prática educativa requer planejamento, que se tome o tempo necessário para indagar, individual e coletivamente, acerca de suas finalidades, compromissos políticos e sobre "o quê se está ensinando ao ensinar". Desta forma será possível ampliar a consciência crítica sobre a prática e desembutir teorias subjacentes a ela, procurando fazê-la melhor, porque mais consistente e coerente.

Assumindo uma perspectiva emancipatória, apoiada em Paulo Freire, e diante das considerações feitas até aqui, cabe perguntar: como iniciar o planejamento de uma disciplina? Uma possibilidade é iniciar por questões amplas, de ordem ético-filosófica: Quais são os sonhos do professor? Quais são os sonhos dos estudantes com quem se trabalhará? Essas perguntas ajudam a vislumbrar o horizonte para o qual se pode, em conjunto, caminhar. Além disso, desses questionamentos iniciais surgirão uma série de outras indagações e anúncios de compromissos a serem assumidos pelos participantes da prática. Paulo Freire escreveu:

Falamos em ética e em postura substantivamente democrática porque, não sendo neutra, a prática educativa, a formação humana, implica opções, rupturas, decisões, estar com e pôr-se contra, a favor de algum sonho e contra outro, a favor de alguém e contra alguém. E é exatamente esse imperativo, que exige a eticidade do educador e sua necessária militância democrática a lhe exigir a 
vigilância permanente no sentido da coerência entre o discurso e a prática. (FREIRE; BETTO; KOTSCHO, 2007, p. 41).

Contudo, quando se trabalha com pessoas, com suas expectativas e sonhos, para além das possibilidades humanizadoras que se abrem, é preciso problematizar com elas os limites da prática educativa que se desenvolve, dimensionando o seu alcance em relação à transformação social e considerando os condicionantes que a tornam, em certa medida, reprodutora do status quo e contraditória.

Outro passo importante é tomar conhecimento da realidade local, indagando a respeito das identidades socioculturais dos educandos, de suas necessidades concretas, em busca de seus temas e preocupações. Esses últimos estarão envoltos nas situaçõeslimite vivenciadas pelos estudantes, como indivíduos e integrantes de diferentes grupos sociais e nas negatividades que obstaculizam o seu ser mais ${ }^{5}$, constituindo-se como pontos de partida obrigatórios do processo formativo crítico. Em Pedagogia da Esperança, Freire apresenta questões desafiadoras, que precisam ser seriamente compreendidas e enfrentadas por educadores que se comprometem com práxis humanizadoras:

\begin{abstract}
Que conteúdos ensinar, a favor de que ensiná-los, a favor de quem, contra que, contra quem. Quem escolhe os conteúdos e como são ensinados? Que é ensinar? Que é aprender? Como se dão as relações entre ensinar e aprender? Que é o saber de experiência feito? Podemos descartá-lo como impreciso desarticulado? Como superá-lo? Que é o professor? Qual seu papel? E o aluno, quem é? E o seu papel? Não ser igual ao aluno significa dever ser o professor autoritário? É possível ser democrático e dialógico sem deixar de ser professor, diferente do aluno? Significa o diálogo um bate-papo inconsequente cuja atmosfera ideal seria a do "deixa como está para ver como fica"? Pode haver uma séria tentativa de escrita e leitura da palavra sem a leitura do mundo? Significa a crítica necessária à educação bancária que o educador que a faz não tem o que ensinar e não deve fazê-lo? Será possível um professor que não ensina? Que é a codificação, qual o seu papel no quadro de uma teoria do conhecimento? (FREIRE, 1992, p. 135).
\end{abstract}

A seleção do conteúdo requer do professor uma visão crítica da realidade, ou seja, clareza científica e posicionamento político que lhe permita estabelecer critérios em relação à qualidade e à consistência das informações, gradação e adequação para os educandos, potencial crítico, atualidade, dentre outros. Cabe-lhe ainda decidir sobre os elementos e dinamizações que auxiliem os sujeitos na prática educativa, na construção, a várias mãos, de uma espiral ascendente de conscientização.

Ressalte-se que as decisões sobre a programação educativa, no bojo de uma educação para a autonomia, precisam ser dialogais, coletivas, públicas, envolver os educandos, o projeto político-pedagógico da instituição, diretrizes de políticas públicas e o contexto comunitário mais amplo. Contudo, cabe ao professor participar ativamente desse processo, de forma a potencializar a democracia e a liberdade na sala de aula. 
RAMOS, B. S. da S.; SAMPAIO, M.; SAUL, A.

Nas disciplinas lecionadas e compreendidas como ações de ensino vinculadas à Cátedra Paulo Freire da UniSantos, adota-se uma concepção praxiológica em relação aos objetivos da educação, o que implica estabelecer fortes conexões entre o ato de conhecer, as necessidades que emergem da vida e das pesquisas dos pós-graduandos e expectativas conjuntas de mudança da realidade. Caso contrário, correr-se-ia o risco de delinear propostas que, embora pudessem ter um valor acadêmico interessante, não carregariam os sentidos e significados capazes de provocar a curiosidade epistemológica dos estudantes e o seu indispensável engajamento na construção de conhecimentos e práticas emancipatórias.

Quanto aos métodos utilizados, esses precisam ser selecionados e organizados coerentemente em relação aos conteúdos selecionados para estudo, tendo em vista que a forma não negue o conteúdo a ser ensinado-aprendido e vice-versa. As escolhas metodológicas também necessitam considerar a realidade da instituição e dos educandos, os recursos disponíveis para a realização das aulas, as diferentes formas e ritmos de aprender e aprendizados que são potencializados e engendrados por um ou por outro método, procedimento ou dispositivo pedagógico, estimulando a criatividade dos sujeitos como fator de humanização.

Para Paulo Freire, as dimensões gnosiológica, criativa, estética e política da prática educativa são indissociáveis e quanto maior for a clareza dessa relação, melhor será a prática pedagógica e mais intensa poderá ser a colaboração do educador na formação dos estudantes. De acordo com o Autor, em diálogo com Shor:

[...] a educação é, por natureza, um exercício estético. Mesmo que não estejamos conscientes disto, enquanto educadores, ainda assim estamos envolvidos num projeto naturalmente estético. $O$ que pode acontecer é que, desatentos ao aspecto estético da educação, nos tornemos maus artistas, mas, não obstante, artistas de algum tipo, na medida em que ajudamos os educandos a ingressar num processo de formação permanente (FREIRE; SHOR, 2008, p. 145).

O professor que se assume como artista, muito mais que um simples técnico, pode, a partir de sua experiência e dos conhecimentos que adquire em sua formação permanente, criar metodologias e métodos, sintetizando e combinado ideias para elevar as condições de conhecer nas quais se encontram os educandos e a sua própria.

Tomar a matriz freireana como referencial, para o planejamento e desenvolvimento de disciplinas acadêmicas, tem possibilitado que os estudantes adotem uma postura autônoma e curiosa diante dos desafios do estudo e da pesquisa. Faz com que demonstrem interesse em debater criticamente os temas geradores que movimentam a prática educativa e compreendam a produção de conhecimento como uma construção política, social e histórica.

Torna-se crucial, portanto, a busca incessante por propostas e práticas pedagógicas radicalmente democráticas, pautadas pelo diálogo e por um rigor que se verifica em tentativas vividamente conscientes de alcançar maior coerência entre palavras proferidas e os gestos realizados.

Evidentemente, assumir os pressupostos de Freire em tempos neoliberais e neoconservadores não é tarefa fácil e nem algo que possa ser realizado de segunda para 
terça-feira ${ }^{6}$. Isso vai exigir enfrentar estruturas autoritárias, rever concepções e práticas estabelecidas, mudar valores, hábitos e crenças, educar os medos e superar dificuldades. Isso requer dos educadores e da sociedade, em diferentes contextos e esferas, compromissos políticos e solidários na direção de uma educação pública popular e democrática. Nesse sentido, exige-se que sejam feitos debates e reflexões que explicitem as intenções, as tensões e os conflitos da sociedade, e que se indague coletivamente que utopia social se quer construir, com o auxílio da educação e o crivo da defesa intransigente da vida e da dignidade humana.

NOtAS DE UMA PEDAGOGIA CAMINHANTE: A CÁTEDRA PAULO FREIRE DA UFSJ E A CIDADE EDUCADORA

\author{
Andar e pensar um pouco, \\ que só sei pensar andando. \\ Três passos, e minhas pernas \\ já estão pensando... \\ (Leminski, 1994, p. 39)
}

Pernas que pensam ao caminhar: a metáfora poética criada por Leminski (1994, p. 39) nos inspira a recompor uma experiência constituída no interior da Cátedra Paulo Freire da Universidade Federal de São João del-Rei, no contexto de uma disciplina do Mestrado em Educação intitulada Epistemologia da Educação Popular em Paulo Freire?. Apoiando-nos na Pedagogia do Oprimido (FREIRE, 1987), como construção de um projeto contra-hegemônico de educação e de sociedade, esta disciplina focaliza a matriz político-pedagógica do pensamento de Paulo Freire. Compreende a Educação Popular como uma paradigma emancipatório enraizado na realidade de vida, na história e na cultura das classes populares, sendo princípio e movimento de mudança e resistência.

Nesta disciplina, assim como em outras frentes de ensino-pesquisa-extensão ${ }^{8}$, temos buscado experimentar a Cidade ${ }^{9}$ como território de resistência e criatividade, o que vem nos aproximando de formas mais democráticas do fazer educativo. Buscamos evidenciar a Cidade como lugar de encontros entre sujeitos que, por meio do diálogo conscientizador, possam encontrar formas possíveis de transformá-la. Como afirma Gadotti (2006, p. 139), "existem muitas energias transformadoras que ainda estão adormecidas por falta de um olhar educativo sobre a cidade". Por isso, afirma ele, precisamos de uma pedagogia da cidade que nos ensine a olhar, a descobrir a cidade, para poder aprender e conviver com ela.

Mas eis que estávamos em fins de 2019 e ainda podíamos caminhar livremente pelas ruas, sem máscaras ou amarras que restringissem a nossa liberdade. Fizemos da Cidade de São João del-Rei a nossa sala de aula. Na composição de uma experiência ético-estética que nos permitisse alcançar a íntima relação entre a Educação Popular e a Cidade como território educativo, caminhamos juntos, professora e estudantes, ao longo de um semestre, pelas ruas e avenidas de São João del-Rei, ocupando diferentes espaços e percebendo, como pela primeira vez, lugares antes vistos. Nas andarilhagens 
coletivas ampliou-se sobremaneira o nosso espaço pedagógico, comumente limitado pelas "paredes" de nossas salas de aula e "muros" de nossa universidade.

Com Paulo Freire $(2018$, p. 36) entendemos que "a presença do educador e dos educandos não se dá no ar". Educadores e educandos se encontram em um determinado espaço pedagógico e este é um dos elementos fundantes da situação educativa. No espaço que construímos juntos, na/e com a Cidade, experimentamos encontros que constituíram, na enunciação de nossos passos, uma espécie de pedagogia caminhante.

Hoje, rememorar essa experiência dialógico-amorosa, é semente de esperança em um amanhã no qual possamos voltar a caminhar por nossas Cidades, explorando as múltiplas possibilidades de vida e de aprendizagens que elas nos oferecem. Do momento em que estamos, rememoramos o ontem ainda tão próximo e vemos emergir, professora e estudantes, como caminheiros que se aproximaram do rumo da terra: leitores-caminhantes que mergulham no universo da Cidade. Cidade que nos (re)faz ao passo em que também é, por nós, (re)feita. Como bem lembra Paulo Freire, "a Cidade somos nós também, nossa cultura, que, gestando-se nela, no corpo de suas tradições, nos faz e nos refaz. Perfilamos a Cidade e somos por ela perfilados" (FREIRE, 2015, p. 30).

$\mathrm{Na}$ cena teórico/metodológica constituída neste quefazer educativo que faz da sala de aula a Cidade, o ato de caminhar deixa de ser ação cotidiana e rotineira e se torna atravessamento ético-estético. Falamos, aqui, de uma tríade de gestos significativos: VER-DIALOGAR-SENTIR. Fundamentados na práxis crítico-dialógica de Paulo Freire, buscamos construir experiências que gestam a indivisibilidade entre teoria e prática; entre reflexão e ação. Caminha-se pela Cidade para (re)conhecê-la e (re)pensá-la, enquanto nos (re)conhecemos e (re)pensamos a nós mesmos, tendo em vista as possibilidades de sua e nossa própria transformação.

No caso em tela, o ato de VER está relacionado ao movimento de afetar e ser afetado pelo olhar. Olhar de quem vê, e, não apenas, olha. Por isso, não basta a forma física do olhar. Para poder ver é preciso assumir o olhar como um modo de compreensão. Compreensão esta, como afirma Gadotti (2006, p. 138), que nos compromete: "não queremos olhar certas coisas da cidade para não nos comprometermos com elas, pois o olhar nos compromete". Daí a importância de caminharmos como quem se compromete com o traçado de uma nova direção.

É o que anunciam Masschelein e Simons (2014, p. 46):

\begin{abstract}
a caminhada é uma atividade física que move ou desloca o olhar (ou seja, faz com que ele abandone a sua posição, ex-põe) ao longo de uma linha arbitrária, ao longo de uma caminho que já existe e que, ao mesmo tempo, traça-se novamente; um caminho em direção a um novo olhar (mas sem orientação ou destino).
\end{abstract}

Nossas andanças pela Cidade, ora conversando pelo caminho, ora partilhando silêncios necessários, nos permitiu, de diferentes maneiras, olhar a Cidade em algumas de suas camadas mais profundas. Cidade histórica, mineira das Vertentes, São João delRei é toda ela cultura. São lendas e "causos", muita história desse nosso Brasil, uma arte infinita em suas diferentes manifestações, e a sui generis convivência entre o sagrado e o profano. Pensar a Educação Popular, objeto de nossa atenção, passou em grande parte por olhar o espaço-tempo da Cidade e nela perceber múltiplas formas de produzir 
cultura, de fazer a história e de viver a vida. Vimos, dialogamos e sentimos, in loco, a Educação Popular como espaço-tempo de vida, de cultura, de comunhão.

A cada caminhada, um local se transformava em sala de aula e nesses diferentes espaços pedagógicos íamos construindo relações teórico-práticas entre os textos lidos/discutidos e a realidade experimentada em nosso entorno. Nesse percurso, o caminho percorrido na Cidade educadora e os temas da Educação Popular emergentes das leituras e dos diálogos construídos pelos caminheiros tomaram forma de uma Cartografia Temática. Esta Cartografia consistiu no exercício de produção/construção de um mapa (em diferentes linguagens possíveis: verbal, visual, verbo-visual, audiovisual, poética, artística, imagética, sonora etc.) que constituísse e resguardasse a memória da experiência que partilhamos na disciplina.

Foram, ao todo, 12 caminhadas e 14 espaços pedagógicos partilhados, incluindo um Largo e sua Praça, a Biblioteca Municipal, o Mercado Municipal, o Teatro Municipal, Museus e Centros Culturais (nos quais se incluem um Conservatório estadual de Música e um Centro de referência musicológica), um Forte histórico e uma das Serras que abraça a Cidade, com suas pinturas rupestres.

Momento muito significativo dessa trajetória foi a nossa caminhada/visita ao Mercado Municipal de São João del-Rei. Tínhamos em mente três problematizações que guiariam a nossa caminhada pelo Mercado: (1) Quais saberes circulam e são construídos no Mercado Municipal de São João del-Rei? (2) Você percebe algum processo educacional relacionado a esses saberes? (3) Qual é a relação entre Cultura e Identidade compreendida a partir de suas andanças pelo Mercado? No trecho a seguir, narrado pela estudante Patrícia em sua Cartografia Temática, podemos nos aproximar da potência do que foi vivenciado naquele experimentar coletivo.

Dia 28 de Agosto de 2019, conhecemos ou reconhecemos dois novos pontos da Cidade. O primeiro deles foi o Mercado Municipal, localizado no Centro Histórico de São João del-Rei. Nesse dia, eu pude reconhecê-lo, considerando que embora frequente aquele local há quinze anos, não, eu não o conhecia. Interessante pensar que até as nossas simples compras semanais, de comida mesmo, para nossa subsistência, são feitas sob a ótica do capital. Saímos com o dinheiro em mãos e o objetivo de comprar nossas verduras, arroz, carne, ovos, sempre na correria de quem já tem tatuado na mente "time is money". E assim, escolhemos nossos tomates sem nem ao menos olhar nos olhos de quem faz a mesma coisa na banca ao lado. Reconhecer o Mercado Municipal foi para mim uma oportunidade de olhar. Olhar para o outro, olhar com o outro. Sentir o cheiro daquele local, o que as pessoas lá conversam, o que vivem, o que sonham, de onde vieram. Academicamente falando, foi possível reconhecer quais saberes circulam e se constroem ou se desconstroem naquele local. A cultura presente ali e a identidade das pessoas que vivem diariamente naquele local (Patrícia Carvalho, estudante de pós-graduação em Educação da UFSJ, Cartografia Temática, 2019). 
A estudante Patrícia nos coloca diante da contradição entre o Mercado, como espaço público tão importante para a vida social, cultural e alimentar de nossa Cidade, e a lógica de mercado que nos assola em nossa própria humanidade. Naquele momento de experiência e reflexão, de partilha coletiva, Patrícia conhece, como se fosse pela primeira vez, aquele lugar tantas vezes frequentado. Para isso, foi preciso exercitar o olhar: ver as pessoas que antes não via, sentir cheiros e sabores que antes não sentia e compreender a imensidão de saberes que pulsam e circulam naquele espaço-tempo de vida da Cidade.

Aqui, também, falamos do DIALOGAR como gesto fundante. Em Paulo Freire, o diálogo só existe na base da relação eu-tu, onde os sujeitos dialogantes ocupam posição de horizontalidade e o gesto dialógico busca ser vivido como ação: palavração (FREIRE, 2001). Caminhamos lado a lado, passo a passo; falamo-nos e escutamo-nos, com liberdade e rigor, buscando o exercício de uma escuta atenta (FREIRE, 1996) que nos permitisse estar em relação com. Os modos de andar pelas ruas e, dialogicamente, vivenciar a experiência ético-estética, de múltiplas formas e variadas intensidades, permitiram que nossos olhares desenhassem uma paisagem própria, modificando a Cidade e a nós mesmos. Algo em torno do "deslocamento" do olhar que a caminhada propicia. Caminhar significa "deslocar o olhar para que possamos ver de uma maneira diferente, para que possamos ver o visível [...] e de maneira que possamos ser transformados" (MASSCHELEIN; SIMONS, 2014, p. 43).

Com Paulo Freire (2015), reafirmamos, para nós mesmos, que a tarefa educativa da Cidade está, em boa medida, relacionada ao tratamento de sua memória. Ao longo da disciplina-experiência, caminhamos por Museus, Memoriais e Centros Culturais de nossa Cidade-Memória. Memória que, segundo Freire (2015, p. 30), não apenas guarda, mas alonga e estende-se às gerações que chegam: "Seus museus, seus centros de cultura, de arte são a alma viva do ímpeto criador, dos sinais de aventura do espírito. Falam de épocas diferentes, de apogeu, de decadência, de crises, da força condicionante das condições materiais".

Desse modo, um de nossos encontros foi realizado no Memorial Tancredo Neves, espaço que assume, por sua responsabilidade, a preservação e a disponibilização do acervo referente à memória do ex-presidente Tancredo Neves, seu filho mais ilustre. $\mathrm{Na}$ cartografia temática de Khalmel Oliveira, intitulada "Caminhos e Diálogos", o estudante nos revela que, já nos primeiros encontros, pôde evidenciar/sentir a intencionalidade dialógica de nossas caminhadas.

Aula N.2 - 21/08/2019 - Nosso segundo encontro aconteceu no Memorial Tancredo Neves. (...) As indicações de leitura para esse encontro somaram-se às discussões anteriores e fizeram a visitação ganhar um significado amplo e valioso. Amplo porque tive a oportunidade de experimentar o sentido da práxis, do quefazer, logo no início das nossas andanças. A indissociável relação entre a fundamentação teórica e a vivência cultural-formativa é certamente a marca de Freire, e estamos a vivenciando no contexto das nossas aulas. Isso me fez atribuir um grande valor para esse momento e para a proposta da disciplina como um todo, porque a visitação ao Memorial me proporcionou uma experiência para além da formação acadêmica, pude ali me situar como sujeito histórico, como sujeito político e, sobretudo, como um cidadão que tem 


\begin{abstract}
direito à Cidade e suas possibilidades educativas. (...) Ao tratar das Cidades educativas Paulo Freire escreve de forma bela acerca dos saberes que ocorrem na Cidade, "saberes de suas experiências feitos, saberes 'molhados' de sentimentos, de emoção, de medos, de desejo" (FREIRE, 2015, p. 22). Esse trecho me remeteu aos sentidos experimentados no transcorrer da visitação ao memorial; imbuído da pedagogia de Freire, pude estabelecer diferentes diálogos, com os colegas, com os sons, com os textos, com as imagens, enfim, um momento marcadamente dialógico (Khalmel Oliveira, estudante de pós-graduação em Educação da UFSJ, Cartografia Temática, 2019).
\end{abstract}

Em nossos caminhos, outro gesto muito caro à práxis freireana, também se evidenciou: o SENTIR. Para Freire (1996), nenhuma formação docente verdadeira pode se fazer alheia, de um lado, ao exercício da criticidade e, de outro, ao reconhecimento do valor das emoções, da sensibilidade, da afetividade. Pensando a formação do corpo consciente (FREIRE, 1987, 2006, 2007; FREIRE; FAUNDEZ, 2011), Freire nos fala de um homem e de uma mulher que existem como um corpo todo: são razão, mas também, sentimentos, desejos, sonhos. Por isso, não basta o olhar da razão ou da razoabilidade, quando se trata de "nós, os humanos" (BRANDÃO, 2015). O que diz respeito ao humano e às suas relações no e com o mundo - incluída aí a educação em toda sua complexidade - só se desvela em camadas outras, mais profundas do que se dá à superfície. É aí, onde a pura razão não alcança e corpo e mente se desafiam a coexistir, que se pode tecer caminhos sensíveis de percepção do mundo à nossa volta.

Em nossa Cidade-sala e em nosso corpo-Cidade sentimos e experimentamos sentimentos e emoções diversas, partilhadas em gestos de solidão-comunhão, pois é "enquanto adverbialmente só que percebo a substantividade de estar com" (FREIRE, 2013, p. 27, grifo do autor). Uma das memórias significativas que trazemos vem à tona a partir de um trecho da Cartografia Temática do estudante Isaias Soares, por ele intitulada como "Caminhografia de afetos com Paulo Freire e com São João del-Rei". Para discutirmos a Pedagogia do Oprimido por meio de uma vivência do Teatro do Oprimido, tendo como sala de aula o Teatro Municipal da Cidade, pedimos aos estudantes que, em suas andanças, prestassem atenção ao olhar e fotografassem algo que os(as) remetesse à opressão em suas múltiplas formas de existir. Eis a narrativa do estudante:

Teatro Municipal de São João del-Rei, uma das construç̃̃es mais imponentes da Cidade foi nosso local do $5^{\circ}$ encontro. Confesso, que para esse encontro eu estava bastante ansioso. Primeiro porque já havia visitado o teatro, mas sempre foi do lado da plateia e nessa visita sabia que ocuparíamos o palco com o Teatro do Oprimido. Anteriormente, a professora Bruna nos propôs que tirássemos uma foto que nós individualmente atribuíssemos o significado de opressão para que servisse de apoio para dinâmica que seria realizada no local. Esse exercício, de pensar a opressão, me tirou um pouco da zona de conforto, afinal todo mundo sabe o que é opressão, mas você já pensou em como faria um recorte dessa 
RAMOS, B. S. da S.; SAMPAIO, M.; SAUL, A.

palavra através da imagem? Pois é, para mim foi uma tarefa difícil. Me fez, durante a semana, tentar perceber onde eu enxergava a opressão na Cidade. Me fez treinar os olhos, para aquilo que eu sabia que existia, mas que nem sempre era visível. A Cidade é cheia de contradições, a Cidade é cheia de opressões, mas nós somos treinados para não enxergá-la, para não se sensibilizar. Andando pela principal avenida da Cidade, mais uma vez na minha bicicleta, vi um morador de rua revirando o lixo, com uma imensa sacola de papelão nas suas costas. Pensei, está aí uma situação de opressão. Nosso sistema capitalista, em que os holofotes são voltados para o lucro e acumulação, tanta casa sem gente, tanta gente sem casa. No momento que parei para fotografar essa cena, fui tomado por um vazio que me revirou o estômago, será que seria justo eu tirar uma fotografia dessa situação para não fazer nada a respeito? (Isaias Soares, estudante de pós-graduação em Educação da UFSJ, Cartografia Temática, 2019).

O sentimento de Isaias anuncia a potência de sentir para poder ver: o estudante experimenta, com seu corpo todo, o comprometimento que o gesto de olhar implica. Em nossa leitura, esse sentimento, que faz "revirar o estômago" quando assumimos a compreensão crítica de nossa realidade, pode desestabilizar o sujeito, levando-o ao encontro da rebeldia necessária à transformação.

Assim amalgamados, VER-DIALOGAR-SENTIR se fazem gestos fundantes da formação humanizadora, implicando-nos a uma ação didática que, aberta à própria reinvenção, se faça, mais e mais, humana.

Prática PEDAGógICA DOCENTE-DISCENTE humANIZAdORA NO CURSO DE PEDAGOGIA DA UECE

Traçar percursos formativos marcados pela radicalidade democrática, em favor de uma ação transformadora e libertadora, pressupõe pautar o planejamento da ação didática e o seu desenvolvimento pelos fios condutores da criticidade, criatividade, curiosidade, amorosidade e protagonismo, elementos constituidores da educação humanizadora de Paulo Freire. Assumindo tais princípios, duas professoras, vinculadas ao Núcleo de Educação Popular do Curso de Pedagogia do Centro de Educação da Universidade Estadual do Ceará (UECE), investiram na busca coletiva para contribuir com a constituição de uma prática pedagógica docente-discente humanizadora de graduandos(as). A docência compartilhada de aulas remotas, no formato síncrono levou em conta que:

As reflexões sobre a formação para a docência no ensino superior ancoradas nos aportes teóricos da pedagogia de Paulo Freire indicam a necessária reflexão com e sobre a realidade da sala de aula na universidade, instigando a compreender e objetivar ações e relações instituidoras de um autêntico processo formador (LIMA e BRAGA, 2016). 
Contando com o apoio de uma monitora e uma estagiária docente (doutoranda do Programa de Pós-graduação em Educação da UECE), a Pedagogia de Paulo Freire se constituiu como disciplina e fundamento de ações e relações gestadas na própria história de estudantes, em seus percursos de inacabada autenticidade, temporalidade e integralidade.

Envidar esforços na superação da prática pedagógica instrumental, conservadora, supostamente neutra, em direção da prática pedagógica humanizadora, demandou uma atuação pautada no exercício da fala-escuta, autoridade docenteliberdade discente. Coube às educadoras reconhecerem que não eram as únicas que possuíam conhecimento acerca do conteúdo que as aproximava do grupo de estudantes - a pedagogia freireana. (FREIRE; SHOR, 2008).

No desejo de vivenciar os princípios e a metodologia da Pedagogia de Paulo Freire na sala de aula, ações e relações dialógicas entre professoras, monitora e estagiária docente foram empreendidas. Para tanto, a sistematização dos conhecimentos prévios dos estudantes acerca da pessoa, obra e pedagogia de Paulo Freire e as inquietações indagadoras do grupo deram o suporte para a elaboração e implementação de um programa diferenciado das turmas anteriores.

Quanto aos conhecimentos que possuíam sobre Paulo Freire, sua obra e epistemologia, os estudantes recém-ingressos na Universidade revelaram saber que Paulo Freire é nordestino, que se formou em Direito, embora nunca tenha exercido a profissão, que se dedicou à pedagogia e a filosofia, embora fosse de classe média, sempre voltou sua atenção a pessoas em condição de pobreza. Sabiam também que ele foi preso e exilado na época da ditadura militar, que durante o exílio, foi professor na Universidade de Harvard, nos Estados Unidos, que sua obra Pedagogia do Oprimido é terceira obra acadêmica mais citada no mundo em trabalhos de ciências humanas, tendo sido concluída no exílio. Os estudantes sabiam que por ter sido filiado ao Partido dos Trabalhadores (PT), Paulo Freire é considerado comunista pela ala conservadora, tanto que foi chamado de "energúmeno" pelo atual presidente do Brasil, Jair Bolsonaro. E finalmente, sabiam que ele foi, é e sempre será Patrono da Educação Brasileira.

Caracterizar o grupo de estudantes, em termos de suas aprendizagens, se constituiu como manifestação de respeito aos seus saberes previamente constituídos e ponto de partida para novos conhecimentos, em matéria de sedimentação, ampliação e novas elaborações individuais e coletivas das contribuições do Autor, instigadas pelas inquietações indagadoras do grupo.

Segundo testemunho da estudante Ellen, ao perguntarem quais as dúvidas, curiosidades ou inquietações os alunos possuíam sobre Paulo Freire e sua pedagogia e, depois, fazerem uma síntese, organizando-as em blocos por aproximação de temáticas, apresentando-as e discutindo cada uma delas com a turma, as professoras "ao longo das aulas, apontaram os caminhos para as respostas", alicerce do processo constitutivo do planejamento participativo.

As inquietações indagadoras da turma gravitaram em torno da problematização: O que caracteriza e como se dá, na prática, a Pedagogia Freireana? Tal questão mobilizou a turma a "analisar os pressupostos da Pedagogia de Paulo Freire que sustentam uma educação voltada para a construção de um mundo humanizado e seus 
RAMOS, B. S. da S.; SAMPAIO, M.; SAUL, A.

desdobramentos na prática", objetivo geral da Disciplina A Pedagogia de Paulo Freire, ofertada aos estudantes do primeiro semestre do Curso de Pedagogia, no semestre letivo $2020.1^{10}$.

Na medida em que as temáticas, conceitos, contextos e perspectivas de compreensão do alcance da Pedagogia Freireana e sua materialidade na prática passaram por ampla discussão e aprovação do grupo, revelou que a micropolítica da sala expressa a posição do(a) professor(a) perante os problemas da divisão social (FREIRE, 2000).

Ao considerar a ação dos sujeitos envolvidos, a prática docente-discente vincula-se a uma lógica de implicação e pertença, por respeitar cada estudante em suas raízes e saberes, relacionando-os com os conteúdos propostos pela disciplina, as professoras contribuíram com práticas pedagógicas docente-discentes de matriz dialógica, humanizadora (BRAGA, 2015).

A Disciplina, então, foi delineada por um processo pedagógico sustentador de aprendizagens significativas, utilizando: exposição dialogada, agenda diária, acolhida, sínteses reflexivas das aulas, estudos individuais e em grupo, debates temáticos, Seminário Integrado, Avaliação da Disciplina e autoavaliação.

Liberdade, respeito, amorosidade na criação de uma atmosfera produtiva em aulas remotas

A aula como espaço e tempo coletivo de formulação e difusão de saberes e cultura encontra na perspectiva crítico-libertadora de Paulo Freire as bases de sua formulação, assegurando uma ação didático-pedagógica calcada na análise da realidade em que os(as) estudantes estão inseridos(as), considerando suas inquietações indagadoras, incertezas e situações-limite vivenciadas, como a timidez ou os múltiplos receios diante da nova condição de universitários, num contexto de afastamento social que impôs um semestre atípico.

Esforçadas para tornar as aulas remotas mais tranquilas e condizentes com as práticas ensinadas por Paulo Freire, as educadoras se mostraram

\begin{abstract}
sempre solícitas, com olhares de empatia (...) fizeram da disciplina dinâmica e participativa que favoreceu para a nossa superação como sujeitos que no início éramos tímidos e retraídos para sujeitos que participam e que são protagonistas do próprio aprendizado. Deram exemplo, agiram de forma ética, nos respeitam como seres humanos e acreditaram em nós (Ellen).
\end{abstract}

A metodologia de ensino, planejada a partir da epistemologia pensada-vivida pelo educador pernambucano, consistiu em superar a visão de que o(a) aluno(a) é um mero(a) espectador(a) no processo de aprendizagem, considerando-o(a) como sujeito ativo do processo de ensinar-aprender (FREIRE, 1996), imiscuído de amorosidade, como alude uma estudante:

Durante todo o semestre pude perceber as professoras, a monitora e a estagiária com um profissionalismo impecável e um afeto que me fazia sentir acolhida e confortável. Todas buscaram sempre nos 
Mesmo em condições adversas, como o ensino por vias remotas, é possível vivenciar uma ação didática delineada pelo respeito, pela amorosidade, criticidade, criatividade, curiosidade, protagonismo, elementos constituidores do diálogo, base fundante da epistemologia freireana, fio condutor do planejamento e da prática pedagógica docente-discente vivenciada na disciplina Pedagogia de Paulo Freire, apostando num processo formativo que fizesse contraposição ao mero treinamento para o uso de técnicas e princípios científicos.

A metodologia usada foi coerente com o que aprendi com Paulo Freire, as professoras nos deram autonomia para falar, debater, escolher o livro que íamos ler, para tomar decisões. A aula era nossa. (Ellen).

$\mathrm{Na}$ metodologia utilizada, senti que minhas opiniões eram realmente levadas em consideração, como na atividade proposta no início do semestre, em que as professoras fizeram um textosíntese de nossas resenhas sobre o nosso conhecimento em relação ao filósofo e pedagogo Paulo Freire (Adelaide).

A percepção das alunas se coaduna com o ponto de vista de um estudante que, mesmo na condição de tetraplégico, considera que a metodologia utilizada "foi boa, uma vez que as professoras estimularam a participação dos(as) estudantes". Com relação ao Seminário Integrado, a turma inteira pôde se envolver no conteúdo estudado", afirmou David, especialmente "na atividade prática e no debate gerado por uma pergunta de cunho problematizador", afirmou Adelaide.

A clareza de que os alunos se mostraram participativos evidencia que, mesmo diante os desafios postos pelo ensino remoto, é possível vivenciar uma metodologia de trabalho integradora e includente, como revela os excertos de falas de outros(as) estudantes:

As leituras, a escrita e os debates foram de grande valor para compreensão e formação dos alunos. Tudo foi de grande aprendizado, os questionamentos que foram levantados, as respostas que foram encontradas e as conversas que se formaram durante o semestre. Acredito que lá no futuro ainda lembraremos desses momentos e voltaremos para gerar novas questões. (Ana Lourdes). 
RAMOS, B. S. da S.; SAMPAIO, M.; SAUL, A.

\begin{abstract}
O que mais favoreceu foi a vontade das professoras em ensinar da forma mais didática e interativa possível, mesmo com todos os empecilhos. (Vitória).

A metodologia aplicada foi única, tornando possível transformar uma sala virtual em um verdadeiro campo fértil de conhecimentos e experiências trocadas entre alunos e professores, o que agregou de forma extremamente positiva em todo o processo de aprendizagem, juntamente com as contribuições excelentes da monitora e estagiária docente. (Valdênia).
\end{abstract}

As marcas positivas da educação como ato crítico de conhecimento, seja no formato de aulas presenciais, seja assumindo feições síncronas, com uso de tecnologias digitais, é uma forma de resistência, por permitir o exercício fecundo da liberdade, do respeito, da amorosidade, pautado na ética, traços da autonomia.

\title{
Avaliação da disciplina e autoavaliação: o exercício da autonomia atrelada à ética
}

O processo vivenciado na disciplina A Pedagogia de Paulo Freire sugere uma reflexão sobre o significado e a relevância dos conteúdos estudados, bem como sobre a forma como ela foi conduzida, impelindo professoras e educandos(as) a fazerem uma avaliação do que e como foi aprendido ou reaprendido, compondo um conjunto de pistas e práticas que poderão contribuir com posturas éticas e estéticas, no campo profissional e no mundo afora.

Durante o semestre pudemos realizar o Seminário Integrado, uma experiência muito enriquecedora. Foi a primeira vez que participei dessa dinâmica e tirei bastante proveito; é uma excelente oportunidade para o trabalho em equipe e o compartilhamento de conhecimento em conjunto, pois todos os discentes participam, sem exceção. (Adelaide).

O desafio de desenvolver uma disciplina interativa, que criasse possibilidades de efetivo aprendizado, mobilizou as professoras a transporem as situações-limite, por meio de atos limite, como apostar na realização do Seminário Integrado, estratégia didática em que todos os alunos assumem distintas tarefas, nas três fases, e, ao final, recebem uma nota única, em processo avaliado por pares, as professoras, monitora e estagiária docente. Tal metodologia contribuiu para retirar "da maioria do corpo discente medos, a vergonha de participar das aulas, de dividir dúvidas, de compartilhar vivências" (Lara).

Ao final do semestre letivo, os estudantes fizeram suas próprias sínteses, selecionando, organizando e registrando sua compreensão sobre cada um dos aspectos sugeridos na avaliação da Disciplina, de onde foram retiradas as percepções acerca da metodologia utilizada, apresentando críticas e sugestões; desempenho das Professoras, monitora e estagiária docente; percepção de como viram a turma; compreensão dos conteúdos abordados, em termos dos princípios freireanos identificados como relevantes para a sua formação humana, acadêmica e/ou profissional na direção de experiências futuras. 


\begin{abstract}
A metodologia utilizada (...) me possibilitou aprender e produzir trabalhos dos quais eu não me imaginava capaz, me trouxe experiências que resultaram em grande amadurecimento e trouxeme amizades que pretendo levar para toda a vida. Por conta da aplicação evidente das professoras, em ensinar e ao mesmo tempo se dispor a aprender conosco, tive diversas oportunidades em expressar o pouco que sei com o resto da turma, opiniões e pensamentos. Tive chance de conhecer obras importantíssimas pela indicação das professoras, obras que contribuíram e continuam a contribuir para minha formação docente, em que me mostraram a necessidade de haver pessoas realmente interessadas em ensinar, em indivíduos que acreditam em um mundo transformado pela educação (...) contribuindo para uma sociedade mais evoluída. (Lívia).
\end{abstract}

A avaliação do próprio desempenho e participação na disciplina, por meio de uma autoavaliação, atribuindo uma nota na escala de 0 a 10 se constitui em exercício formador de revisão do alcance do próprio desempenho na disciplina, em termos dos avanços e limites do seu processo de aprendizagem, tendo como critérios balizadores a participação, o envolvimento, a assiduidade nas aulas e o cumprimento das tarefas propostas.

\begin{abstract}
Cheguei bem tímida, não conhecia Paulo Freire, não estava acostumada a pensar de forma crítica, não sabia bem como escrever uma síntese, estava acostumada apenas a copiar e aceitar o conteúdo apresentado na aula e confesso que cheguei desesperançosa por ouvir de outros professores que essa é uma profissão frustrada. Mas agora saio com um olhar mais esperançoso para a educação, estou tentando me questionar mais, estou buscando ser mais curiosa, a ter um olhar mais humano, empático, aprendi que estamos sempre no estado de aprendiz, que não sabemos de tudo. Saio dessa disciplina um pouco mais humana e feliz pela minha escolha (Ellen).
\end{abstract}

A nova condição de pessoa curiosa, empática diante da condição do outro, questionadora da realidade e de si mesma, assumida pela universitária caloura, indica a assunção de características constituidoras da humanização em Paulo Freire, a partir da participação ativa como sujeito do ato crítico de conhecimento.

Ao perceber-se em permanente condição de aprendiz da prática docente e da vida, a estudante se coloca em formação permanente na acepção freireana, que leva em conta a diversidade de contextos concretos, mobilizando saberes teóricos e práticos já aprendidos e permitindo construir novos saberes, pela mediação da análise crítica da realidade, com vistas à transformação da sociedade e de si mesmo. (SAUL e SAUL, 2018).

A apreensão crítica de ações e relações vivenciadas no espaço pedagógico, intencionando "a superação das condições de exploração e rotina, com suporte na leitura constante, análise, interpretação, escrita e reescrita da realidade" (LIMA e BRAGA, 2016, p. 80) constituem a formação permanente de base freireana. 
RAMOS, B. S. da S.; SAMPAIO, M.; SAUL, A.

A defesa da autoria criadora reafirma o caráter político do ato de educar, cabendo considerar os limites da ação didática vivenciada em contexto da pandemia, como dificuldades apresentadas pelas docentes quanto à navegação na plataformas do Google e o excessivo tempo dedicado a novas aprendizagens do uso das tecnologias digitais. De parte dos alunos, falta de concentração com o número exacerbado de tempo de acesso às telas, ambiente familiar marcado por situações adversas, como desemprego, adoecimento e movimentação doméstica. Durante certo momento das aulas, foi indicado por uma aluna que o não acompanhamento de todas as mensagens postadas no chat dificultou a aprendizagem,

O que me incomodou em certo momento foi um pouco de desatenção ao Chat do Meet, enquanto se decorria as falas das professoras, pois em certos momentos se deixava de "escutar" as dúvidas de alguns alunos, uma sugestão para resolver esse problema seria uma das professoras ficar responsável por olhar o chat enquanto a outra estivesse falando, (Leuziane).

A escuta sensível acerca dos limites da prática pedagógica avaliada contribuiu com o rigor dialógico na ação didática humanizadora, permitindo às educadoras enveredarem em movimentos de busca de superação de alguns desafios na atuação junto a novas turmas e disciplinas, respeitando-se os limites da atuação docente.

Quando o(a) professor(a) recorre ao diálogo como elemento fundante do planejamento, a aula se configura como espaço-tempo de reinvenção do conhecimento e da sociedade, contribuindo para que os/as estudantes exerçam o poder de produzir conhecimento, reafirmando seu poder de refazer a sociedade (FREIRE, 2000).

A aprendizagem que fica é de que ajudar os alunos a dizer a sua palavra, a pronunciar-se é elemento importante do diálogo em Paulo Freire (1996), que reconhece a autoridade docente na associação com a liberdade discente, permeada pela necessidade e disposição de construir no coletivo. Decidir juntos contribui para que os sujeitos da prática pedagógica tomem para si a tarefa de fazer valer o que foi acordado, assumindo as deliberações tomadas.

\section{CONSIDERAÇÕES FINAIS}

Partindo da Pedagogia do Oprimido como obra de referência coletiva, ampliada pelo conjunto de textos freireanos que formam a base de nossos estudos, temos experimentado o desafio de conhecer e vivenciar a práxis político-pedagógica de Paulo Freire, radicalmente humana e orientada pela luta por justiça social. Desse modo, buscamos construir ações didáticas que, a ela coerentes, encontrem no diálogo problematizador uma forma conscientizadora de pensar-agir sobre o mundo e sobre nós mesmos.

Esse é o espírito que alimenta as três experiências que foram compartilhadas neste artigo. Por meio delas, à profusão e à extensão das atividades realizadas, infundese aquilo que, a nosso ver, agita os sentidos destas ações em seu caráter de intensidade: o eu com os outros eus que nos constituem em relação, nos rastros de uma formação alteritária e dialógica. Por isso, diante do inacabamento que nos alimenta e desafia a continuar percorrendo os caminhos da práxis freireana, no interior de nossas 
universidades, (re)atamos aqui os "nós" que fortaleceram e viabilizaram os caminhos da presente publicação.

Segundo Apple (2017, p. 912), as lutas precisam ser disputadas em múltiplos lugares e a partir de diferentes estratégias, na perspectiva de conectá-las umas às outras, "como parte de um movimento maior para construir e defender modos críticos de participar na construção e defesa de espaços mais críticos e democráticos". Nessa linha de entendimento, compreendemos as práticas crítico-dialógicas que temos compartilhado como elos que conectam as nossas lutas no campo da educação libertadora.

Artigo recebido em: 01/04/2021

Aprovado para publicação em: 29/06/2021

TRACES OF PAULO FREIRE'S PEDAGOGY IN THE HIGHER EDUCATION CLASSROOM: DIALOGICAL RIGOR IN HUMANIZING DIDACTIC ACTION

ABSTRACT: In this article we discussed the humanizing didactic in higher education, searching for traces of Freirean dialogical rigor in experiences lived by the authors in their institutions. Following the paths of Freirean praxis, we presented the assumptions and thematic categories that guide teaching actions experienced during Undergraduate and Postgraduation Education taking Paulo Freire's critical-dialogical matrix as a reference for the planning and development of academic subjects. Within the context of the classroom, we presented and discussed two proposals of didactic actions, one presential and the other one remote, which both seek to share possible paths for the formation of humanizing relations between teachers/professors and students who are involved in the authentic search for knowledge. The basis of this article is the relational experience that has allowed the authors to participate in a collaborative and collective network that connects our actions and strengthens our struggles in the field of liberating education.

KEYWORDS: Higher Education. Didactic Action. Dialogue. Paulo Freire.

RASGOS DE LA PEDAGOGÍA DE PAULO FREIRE EN EL AULA DE LA EDUCACIÓN SUPERIOR: EL RIGOR DIALÓGICO EN LA ACCIÓN DIDÁCTICA HUMANIZADORA

RESUMEN: En este artículo, discutimos la acción didáctica humanizadora en la Educación Superior, buscando rasgos del rigor dialógico freireano en experiencias vividas por los autores en sus instituciones de origen. Siguiendo los caminos de la praxis freireana, presentamos los supuestos y las categorías temáticas que orientan las acciones docentes en la Educación de Grado y Postgrado, teniendo la matriz crítico-dialógica de Paulo Freire como referencia para la planificación y el desarrollo de las disciplinas académicas. En el ámbito del aula, presentamos y discutimos dos propuestas de acción didáctica, una presencial y otra a distancia, que buscan compartir posibles caminos para la construcción de relaciones humanizadoras entre profesores y alumnos implicados 
RAMOS, B. S. da S.; SAMPAIO, M.; SAUL, A.

en la auténtica búsqueda del conocimiento. La base de este artículo es la experiencia relacional que ha permitido a los autores participar en una red colaborativa y colectiva de construcción de conocimiento, que conecta nuestras acciones y fortalece nuestras luchas en el campo de la educación liberadora.

PALABRAS CLAVE: Educación Superior. Acción Dialógica. Diálogo. Paulo Freire.

\section{NOTAS}

1 - O uso deliberado do adjetivo freireano e flexões, assumido nesse texto e em produções que temos desenvolvido, é uma questão de preferência, pela compreensão de que a manutenção da grafia integral do sobrenome do autor destaca com maior vigor a procedência das produções: a matriz de pensamento de Paulo Freire. Em alguns redutos acadêmicos significativos seguiu-se, pois, o seguinte critério: à ortografia original do antropônimo, foi acrescentado o sufixo ano, resultando no adjetivo freireano.

2 - O projeto de remição penal por meio da leitura consiste em desenvolver propostas e práticas de mediação de leitura junto a pessoas presas, realizadas por alunos e professores da Universidade Católica de Santos, Defensores Públicos desse município e pessoas da comunidade que queiram integrar o projeto. A intenção é construir situações mutuamente pedagógicas, nas quais, diferentes saberes são produzidos e relações humanizadoras são constituídas em processos decorrentes de curadoria de obras literárias, estudo e discussão dessas obras, produção e correção de resenhas dos livros lidos, que resultam, também, em dias de pena remidos para as pessoas presas.

3 - De acordo com Silva (2004), temas geradores não são temáticas motivacionais que se limitam a satisfazer curiosidades ingênuas (Freire), recursos didáticos para melhor atrair a atenção dos alunos e, muitas vezes, de forma sub-reptícia, introduzir conteúdos pré-estabelecidos a partir de critérios que desconsideram a realidade concreta dos alunos. São objetos de estudo selecionados no processo de investigação junto à comunidade e a partir de seu caráter significativo, conflituoso e contraditório. São limites que a comunidade possui de intervir concretamente em situações de desumanização por ela vivenciada. (SILVA, 2004, p. 162).

4 - Na acepção freireana, o vocábulo "quefazer" expressa a inseparabilidade entre reflexão e ação transformadora, em uma perspectiva praxiológica.

5 - Para Freire (1987) ser mais é um movimento para a humanização dos homens, que é sua vocação histórica. Relaciona-se com a compreensão filosófica do ser humano como projeto, como devir, em processo constante de busca e aprofundamento de conhecimentos sobre si próprio e sobre o mundo, em uma perspectiva crítica de afirmação e liberdade. Freire acrescenta ainda que: "a busca do ser mais, porém, não pode realizar-se no isolamento, no individualismo, mas na comunhão, na solidariedade dos existires, daí que seja impossível dar-se nas relações antagônicas entre opressores e oprimidos." (FREIRE, 1987, p. 74-75).

6 - Expressão coloquialmente utilizada por Paulo Freire para dizer da impossibilidade de que mudanças duradouras e significativas sejam feitas de forma imediata, sem a necessária experiência do tempo e dos processos históricos.

7 - Disciplina ministrada no Programa de Pós-Graduação em Educação da Universidade Federal de São João del-Rei, no segundo semestre de 2019, pela Profa. Bruna Sola da Silva Ramos, como ação de ensino vinculada à Cátedra Paulo Freire da UFSJ, da qual participaram 11 estudantes do Mestrado em Educação, 4 estudantes em regime especial de disciplina isolada, 1 ex-aluna do Mestrado em Educação e 1 servidora técnico-administrativa da Universidade Federal de 
Pernambuco (UFPE), que, à época, realizava processo de licença capacitação na Universidade Federal de São João del-Rei (UFSJ).

8 - A exemplo da experiência comunicativo-extensionista intitulada Caminhar e ler a Cidade: juventude e corpos conscientes no enfrentamento da vulnerabilidade social, desenvolvida no ano de 2019, na qual apresentamos os Círculos de Leitura Crítica como instrumento metodológico propício ao posicionamento consciente dos sujeitos diante de sua realidade (RAMOS; FERREIRA; RODRIGUES; 2020).

9 - Optamos por grafar Cidade com "c" maiúsculo, assim como Paulo Freire fez em sua obra Política e Educação (FREIRE, 2015). Cidade é substantivo próprio e, como tal, tem caráter singular, sendo fruto da opção política que dá contorno à sua existência. Desse modo, não há neutralidade no fazer-se da Cidade: ela se constitui como um ato político, jamais apenas técnico, respondendo a um determinado projeto de sociedade, de sujeito, de educação.

10 - No contexto da pandemia causada pelo novo coronavírus, a oferta da disciplina A Pedagogia de Paulo Freire que, anteriormente, se dava de forma eletiva para acadêmicos(as) do quarto semestre em diante do Curso de Pedagogia, em 2020 foi designada para todos(as) os(as) estudantes do primeiro semestre e alguns(mas) concludentes, somando um total de 42 pessoas matriculadas.

\section{REFERÊNCIAS}

APPLE, Michael W. A luta pela democracia na educação crítica. Revista e-Curriculum, São Paulo, v. 15, n. 4, p. 894-926 out./dez. 2017.

BRAGA, Maria Margarete Sampaio de Carvalho. Prática Pedagógica Docente-Discente: traços da pedagogia de Paulo Freire na sala de aula. Recife: UFPE, 2015.

BRANDÃO, Carlos Rodrigues. Nós, os humanos: do mundo à vida, da vida à cultura. São Paulo: Cortez, 2015.

FREIRE, Paulo. Pedagogia do oprimido. Rio de Janeiro: Editora Paz e Terra, 1987.

FREIRE, Paulo. Pedagogia da esperança: um reencontro com a pedagogia do oprimido. Rio de Janeiro: Editora Paz e Terra, 1992.

FREIRE, Paulo. Pedagogia da autonomia: saberes necessários à prática educativa. São Paulo: Paz e Terra, 1996.

FREIRE, Paulo. Pedagogia da indignação. São Paulo: UNESP, 2000.

FREIRE, Paulo. Pedagogia dos sonhos possíveis. São Paulo: Editora UNESP, 2001.

FREIRE, Paulo. A Educação na Cidade. 7. ed. São Paulo: Cortez, 2006. 
RAMOS, B. S. da S.; SAMPAIO, M.; SAUL, A

FREIRE, Paulo. Ação cultural para a liberdade: e outros escritos. 12 ed. São Paulo: Paz e Terra, 2007.

FREIRE, Paulo. À sombra desta mangueira. 11. ed. Rio de Janeiro: Paz e Terra, 2013.

FREIRE, Paulo. Política e Educação. 2. ed. São Paulo: Paz e Terra, 2015.

FREIRE, Paulo. Pedagogia do Compromisso: América Latina e Educação Popular. São Paulo: Paz e Terra, 2018.

FREIRE, Paulo; BETTO, Frei, KOTSCHO, Ricardo. Essa escola chamada vida: depoimentos ao repórter Ricardo Kotscho. São Paulo: Ática, 2007.

FREIRE, Paulo; FAUNDEZ, Antonio. Por uma pedagogia da pergunta. 7. ed. São Paulo: Paz e Terra, 2011.

FREIRE, Paulo; SHOR, Ira. Medo e ousadia: o cotidiano do professor. São Paulo: Editora Cortez, 2008.

GADOTTI, Moacir. A escola na cidade que educa. Cadernos Cenpec | Nova série, [S.I.], v. 1, n. 1, p. 133-139, mai. 2006.

GATTI, Bernadete A. Formação de grupos e redes de intercâmbio em pesquisa educacional: dialogia e qualidade. Revista Brasileira de Educação. n. 30, p. 124-132. set./dez. 2005.

LEMINSKI, Paulo. La vie em close. 5. ed. São Paulo: Brasiliense, 1994.

LIMA, Maria Socorro Lucena; BRAGA, Maria Margarete Sampaio de Carvalho. Relação ensino-aprendizagem da docência: traços da Pedagogia de Paulo Freire no Ensino Superior. Educar em Revista, Curitiba, Brasil, n. 61, p. 71-88, jul./set. 2016.

MASSCHELEIN, Jan; SIMONS, Maarten. A pedagogia, a democracia, a escola. Belo Horizonte: Autêntica Editora, 2014.

RAMOS, Bruna Sola da Silva; FERREIRA, Magda Lombardi; RODRIGUES, Lucas Rocha de Brito. Paulo Freire e a leitura crítica da Palavramundo no enfrentamento da vulnerabilidade social. In: Educação \& Linguagem, v. 23, n. 2, p. 119-140, jul./dez. 2020.

SAUL, Ana Maria; SAUL, Alexandre. Uma trama conceitual centrada no currículo inspirada na pedagogia do oprimido. In: Revista e-Curriculum, v. 16, n. 4, p. 42-74, 2018. Disponível em: <shorturl.at/tADM4>. Acesso em: 16 maio 2021.

SILVA, Antônio Fernando Gouvêa da. A construção do currículo na perspectiva popular crítica: das falas significativas às práticas contextualizadas. 2004. Tese 
(Doutorado em Educação: Currículo) - Pontifícia Universidade Católica de São Paulo (PUC-SP). São Paulo.

Bruna Sola da Silva Ramos. Professora Associada do Departamento de Ciências da Educação e do Programa de Pós-Graduação em Educação da Universidade Federal de São João del-Rei (UFSJ). Doutora em Educação pela Universidade do Estado do Rio de Janeiro (UERJ). Pós-doutorado em Educação pela Universidade Federal de Pernambuco, sob a supervisão de Maria Eliete Santiago. Coordenadora da Cátedra Paulo Freire da UFS e líder do Grupo de Estudos Críticos do Discurso Pedagógico (UFSJ/CNPq).

Orcid: https://orcid.org/0000-0002-9478-9393

E-mail: brunasola@ufsj.edu.br

Margarete Sampalo. Professora Adjunta do Curso de Pedagogia do Centro de Educação (CED) e do Mestrado Acadêmico Intercampi em Educação e Ensino (MAIE) da Universidade Estadual do Ceará (UECE). Doutora em Educação pela Universidade Federal de Pernambuco (UFPE). Pós-doutorado em Educação: Currículo da PUC/SP. Coordena o Grupo de Estudo Pedagogia de Paulo Freire (GEPAF). Membro da Cátedra Paulo Freire da UFPE. Autora do livro Prática pedagógica docente-discente e humanização: traços da pedagogia de Paulo Freire na sala de aula. Co-autora do livro Didática e docência: aprendendo a profissão.

Orcid: https://orcid.org/0000-0002-0704-0131

E-mail:margarete.sampaio@uece.br

AleXandre Saul. Professor do Programa de Pós-Graduação Stricto Sensu em Educação (Mestrado/Doutorado) e Coordenador da Cátedra Paulo Freire da Universidade Católica de Santos (UCS). Doutor em Educação: Currículo pela PUC-SP. Líder do Grupo de Pesquisa Currículo e Formação de Professores: diálogo, conhecimento e justiça social (UCS/CNPq).

Orcid: https://orcid.org/0000-0003-0021-8934

E-mail:asaul@unisantos.br

Este periódico utiliza a licença Creative Commons Attribution 3.0, para periódicos de acesso aberto (Open Archives Initiative - OAI). 